\title{
Tip 1 Diyabetli Hastalarda Mikroalbuminüri ve 24 Saatlik Kan Basıncı Monitörizasyonu Arasındaki İlişkinin Değerlendirilmesi
}

\section{Relationship Between Microalbuminuria and 24-hour Blood Pressure Monitoring in Patients with Type 1 Diabetes}

\author{
Mehtap CELAKIL ${ }^{1}$
}

1 Hatay Devlet Hastanesi Çocuk Nefroloji Kliniği, Hatay, Türkiye

Öz.

Amaç: Diyabetik nefropati tip1 diyabetin(DM) önemli mortalite ve morbidite nedenlerindendir. Nefropatinin seyrini belirleyen en önemli göstergeler mikroalbuminüri ve hipertansiyondur. Bu çalışmanın amacı, tip 1 DM'l i çocuklarda ve ergenlerde 24 saatlik ayaktan kan basıncı izleme(24sa holter) ile mikroalbuminüri korelasyonu ve nefropati üzerindeki prognostik faktörleri değerlendirmektir.

Materyal ve metod: Tip 1 DM tanısı ile takipli 129 hastanın dosyası retrospektif olarak tarandı. 24 saatlik kan basıncı holteri takılmış, takip süresi> 3yıl, tanı yaşı 7-18 olan, tip1 DM ye ek bir kronik hastalığı bulunmayan 89 hasta çalışmaya dahil edildi. Hastalar mikroalbuminürisi olan ve olmayan olmak üzere 2 gruba ayrıldı. Bu hastalar demografik (yaş, cinsiyet, tanı yaşı, takip süresi, sosyokültürel düzey) ve klinik özellikler(24 sa holter sonuçları, retinopati varlığı, ekokardiyografi bulguları, hemoglobin A1c düzeyleri, kronik böbrek hastalığı) açısından karşılaştırıldı.

Bulgular: Hastaların 56(\%62,9)'sında mikroalbuminüri varken, 33(\%37,1) hastada mikroalbuminüri yoktu. Mikroalbuminüri olan $12(\% 21,4)$ hastada sistolik, $4(\% 7,1)$ 'ünde diastolik, 3(\%5,3)'ünde sistolik ve diastolik hipertansiyon mevcuttu. $31(\% 55,3)$ hastanın sistolik ve/veya diastolik hipertansiyonu yoktu. Ancak bu 31 hastanın 18(\%58)'i sistolik non-dipper, 4(\%12,9)'ü diastolik non-dipperdı. Mikroalbuminüri olmayan 33 hastanın $22(\% 66,6)$ 'sinin 24 saatlik tansiyon holteri ise non-dipper idi. Ebeveynlerden en az birinin üniversite mezunu olduğu hasta sayısı mikroalbuminürik grupta $3(\% 5,3)$ iken, mikroalbuminürik olmayan grupta anlamlı derecede yüksekti $(p<0.01)$.

Sonuç: Tip 1 DM tanılı hastalarda diabetik nefropatinin takibi olarak mikroalbuminürinin yanında 24saatlik tansiyon holteri yapılması erken tanı için gerekli ve önemli olabilir.

Anahtar Kelimeler: Tip 1 diyabet, Mikroalbuminüri, Diyabetik nefropati, Prognoz

Abstract

Background: Diabetic nephropathy is leading cause of mortality and morbidity of type 1 diabetes mellitus (DM). The most important indicators that determine the progression of nephropathy are microalbuminuria and hypertension. The aim of the study is to assess the role of blood pressure by ambulatory blood pressure monitoring (ABPM) in children and adults with type $1 \mathrm{DM}$ and its correlation with microalbuminuria and assess the prognostic factors on nephropathy.

Materials and Methods: The files of 129 patients followed-up with the diagnosis of type 1 DM were reviewed retrospectively. 89 patients with a 24-hour blood pressure holter, a follow-up time $>3$ years, a diagnosis age of 7 18 and no chronic disease in addition to type 1 DM were included in the study. The patients were divided into two groups, with and without microalbuminuria. These patients were compared in terms of demographic (age, gender, age of diagnosis, duration of follow-up, sociocultural level) and clinical features(24-h ABPM, presence of retinopathy, eco findings, hemoglobin A1c levels, chronic kidney disease).

Results: 56 patients had microalbuminuria, while 33(37.1\%) patients din not have microalbuminuria. $12(21.4 \%)$ patients with microalbuminuria had systolic, $4(7.1 \%)$ had diastolic and $3(5.3 \%)$ had both systolic and diastolic hypertension. 31(55.3\%) patients didn't have systolic or diastolic hypertension.18 (58\%) of these 31 patients were systolic non-dipper and 4(12.9\%) were diastolic non-dipper. 22(66.6\%) of 33 patients without microalbuminuria had non-dipping phenomenon. While the number of patients with at least one of the parents graduated from university was $3(5.3 \%)$ in the microalbuminuric group, it was significantly higher in the nonmicroalbuminuric group $(p<0.01)$.

Conclusion: In patients with type $1 \mathrm{DM}$, a 24-h ABPM may be necessary and important for early diagnosis in addition to microalbuminuria as a follow-up of diabetic nephropathy.

Key words: Type 1 diabetes, Microalbuminuria, Diabetic nephropathy, Prognosis

\section{Sorumlu Yazar I \\ Corresponding Author}

Mehtap ÇELAKIL

Hatay Devlet Hastanesi Çocuk Nefroloji , Hatay, Türkiye

\section{Tel: 05075620063 \\ e-mail :mehtapcelakil@yahoo.com}

Geliş tarihi / Received:

13.04.2020

Kabul tarihi / Accepted: 04.06.2020

DOI: $10.35440 /$ hutfd. 719246 


\section{Giriş}

Diyabetik nefropati tip 1 diyabetin (DM) en sık mikrovasküler komplikasyonudur (1). Genellikle diyabetin süresi ile ilişkili olup tanıdan sonraki 15-20 yıl içerisinde ortaya çıkmaktadır ve erişkin dönemde son dönem böbrek yetmezliğine(SDBY) neden olmaktadır (2). Günümüzde kontrolsüz diyabetlerin sayısındaki artış ve tanı yaşının azalması ile birlikte adult dönemde de nefropati sıkığı giderek artmaktadır. Bu nedenle adult dönemde bu hastalarda diyabetik nefropatinin erken dönemde saptanması ve kontrol altına alınması SDBY'ye ilerlemeyi önemli ölçüde azaltmaktadır(3). Mikroalbuminüri varlığı diyabetik nefropatinin en erken bulgusu olarak kabul edilse de yapılan birçok çalışmada hastaların tansiyon değerlerindeki bozulmanın mikrolabuminüriden önce başladığı gösterilmiş ve nefropati gelişimi için risk faktörleri arasına girmiştir $(1,3)$.Özellikle tansiyondaki gece değerlerindeki bozulma en erken bulgu olarak kabul edilmiş ve diyabetin diğer mikrovaskuler komplikasyonları ile ilişkilendirilmiş̧ir $(2,4)$. Çalışmamızda tip 1 DM tanısı ile takipli olup tansiyon değerlerinde bozukluk olduğundan şüphe edilen hastalarda diyabetik nefropati olup olmadığını ve bunu etkileyen prognostik faktörleri araştırmayı amaçladık.

\section{Materyal ve Metod}

Tip 1 DM tanısı ile çocuk endokrinoloji polikliniğinde takipli ve rutin poliklinik muayenesinde ölçülen tansiyon değerleri yaş cinsiyet ve boya göre>90persentil olan veya spot tek ölçümde bakılan idrarda mikroalbuminüri saptanması üzerine çocuk nefroloji polikliniğine yönlendirilen 129 hastanın dosyaları retrospektif olarak tarandı. Tekrarlayan ölçümlerde 2019 yılı boyunca 24saatlik kan basıncı holteri takılmış olan 103 hastadan takip süresi > 3yıl, tanı yaşı 7-18 olan, tip1 DM ye ek bir kronik hastalığı bulunmayan 89 hasta çalışmaya dahil edildi. Çalışmanın yapılması için gerekli izin Hatay Devlet Hastanesinden 29634685-929 sayı numarası ile 16/04/2020 tarihinde alınmıştır.

24 saatlik tansiyon holteri takılan ve çalışmaya alınan 89 hasta mikroalbuminürisi olan ve olmayan olmak üzere 2 gruba ayrıldı. Bu hastalar demografik(yaş, cinsiyet, tanı yaşı, takip süresi, sosyokültürel düzey) ve klinik özellikler(24 saatlik tansiyon holter sonuçları, retinopati varlığı, ekokardiyografi (eko) bulguları, hemoglobin $\mathrm{A} 1 \mathrm{c}(\mathrm{HbA} 1 \mathrm{c})$ düzeyleri, kronik böbrek hastalığı) açısından karşılaştırıldı. Mikroalbuminüri, en az bir ay arayla toplanan üç ayrı 24 saatlik idrar örneğinden belirlenerek nefelometrik yöntemle ölçüldü. Üç numuneden en az ikisinde idrarda $30-300$ mg/ gün albümin atılımı mikroalbuminüri olarak kabul edildi.

Yaş ve cinsiyete göre oluşturulan standart persentil eğrileri baz alınarak bakılan vücut kitle indeksi $>95$ persentil olan hastalar obez kabul edildi. HbA1C düzeyi 22.5-46.5 $\mathrm{mmol} / \mathrm{mol}(\% 4.2-\% 6.4)$ normal kabul edildi.

Çocuk nefroloji polikliniğimizde 24 saatlik kan basıncı holteri, portatif bir otomatik monitör kullanılarak osilometrik yöntemle ölçülür (Spacelabs ABPM Model no: 90207; SpaceLabs Medical, Redmond, WA). Mevcut üç boyuttan seçilen uygun bir manşon, baskın olmayan kola bağlanır. Ölçümler gündüz 20 dakikada bir ve gece 30 dakikada bir gerçekleştirilir. Farklı yatak istirahat alışkanlıklarına göre önyargıları ortadan kaldırmak için, gün 08:00- 20:00 arasındaki gündüz dönemi ve 00:00-07:00 arasındaki gece dönemi olarak tanımlanır. Kan basıncı yükü, uyanıklık ve uyku dönemleri için ayarlanan yaş, cinsiyet ve boy için normalin üst sınırını aşan toplam (kan basıncı) KB ölçümlerinin yüzdesi olarak tanımlanır. \% 25 veya daha fazla kan basıncı yükü hipertansiyon olarak kabul edilir. Bireysel nokturnal KB düşüşlerini hesaplamak için her bir hastada nokturnal ortalama (saat 00:00-07:00 arası), gündüz ortalaması (saat 08:00-20:00 arası) ile karşılaştıııı ve fark gündüz ortalaması yüzdesi olarak ifade edilir. Gece düşüşü, uyku süresi boyunca KB azalması en az $\% 10$ olarak tanımlanır. Avrupa referans standartları kullanılarak sistolik $\mathrm{KB}(\mathrm{SKB})$, diyastolik $\mathrm{KB}(\mathrm{DKB})$, ortalama arter basıncı(OAB) ve kalp atış hızı için standart sapma skoru (SDS) değerleri kullanılarak KB'nin boy, cinsiyet ve yaşa bağımlılı̆ı düzeltilir. Amerikan Pediatri Akademisinin 2017'deki güncel hipertansiyon klavuzuna göre hipertansiyon tanımı ise sistolik ve/veya diyastolik KB'nin klinik ölçümlerde 95. persantil ve üzerinde olması olarak tanımlanmıştır ve bu değerler baz alınmıştır.

\section{İstatistiksel değerlendirme}

IBM SPSS 20.0 (IBM Corp., Armonk, NY, USA) paket programı ile yapıldı. Normal dağılıma uygunluk KolmogorovSmirnov Testi ile değerlendirildi. Normal dağılım varsayımı sağlanmadığından nümerik değişkenler medyan(25.-75. persentil) olarak verildi. Kategorik değişkenler ise frekans(yüzde) şeklinde ifade edildi. Gruplar arasındaki farkIılık normal dağılım varsayımı sağlanmadığından Mann Whitney $U$ testi ile belirlendi. Kategorik değişkenler arasındaki ilişkiler Ki-kare analizi(pearson korelasyon analizi) ile değerlendirildi. İki yönlü hipotezlerin testi için $p<0.05$ istatistiksel önemlilik için yeterli kabul edildi.

\section{Bulgular}

Çalışmaya toplam 89 hasta dahil edildi. Hastaların 41'i erkek(\%46), 48'i kız(\%54)'dı. Tanı yaşı median 13 (7-15), takip süresi median 7 (3-15) seneydi. Hastaların $56(\% 62.9)$ 'sında mikroalbuminüri varken, $33(\% 37.1)$ hastada mikroalbuminüri yoktu. Mikroalbuminürisi olan grubun günlük mikroalbuminüri düzeyi ortalama 190mg/gün idi.24 saatlik tansiyon holter sonuçlarının mikroalbuminürisi olan grup ile mikroalbuminürisi olmayan grup karşılaştırıması tablo 1'de verilmiştir. Buna göre mikroalbuminüri saptanan 56 hastanın 12(\%21,4)'sinde sistolik,4(\%7.1)'ünde diastolik, 3(\%5.3)'ünde sistolik ve diastolik hipertansiyon mevcuttu. 31(\%55.3) hastanın sistolik ve/veya diastolik hipertansiyonu yoktu. Ancak bu 31 hastanın 18(\%58)'i sistolik non-dipper,4(\%12.9)'ü diastolik non-dipper olarak bulundu. 
Tablo 1. Mikroalbuminürisi olan ve olmayan hastaların 24saatlik kan basıncı sonuçlarının karşılaştırılması

\begin{tabular}{l|l|l|l}
\hline & $\begin{array}{l}\text { Mikroalbuminüri } \\
\text { olanlar(n) }\end{array}$ & $\begin{array}{l}\text { Mikroalbuminüri } \\
\text { olmayanlar(n) }\end{array}$ & $\begin{array}{l}\mathbf{P} \\
\text { değeri* }^{*}\end{array}$ \\
\hline $\begin{array}{l}\text { 24saat tansiyon } \\
\text { holter }\end{array}$ & & & \\
$\begin{array}{l}\text { Sistolik HT } \\
\text { Diastolik HT }\end{array}$ & 12 & 2 & $\begin{array}{l}p<0.05 \\
p<0.05\end{array}$ \\
\hline $\begin{array}{l}\text { Gece kan basıncı } \\
\text { Sistolik HT }\end{array}$ & 4 & - & \\
Diastolik HT & 21 & 13 & $p>0.05$ \\
*:Pearson ki-kare testi ile $p<0.05$ anlamlı kabul edilmiştir & $p>0.05$ \\
\hline
\end{tabular}

Tablo 2. Mikroalbuminürisi olan ve olmayan grupların 24 saatlik gündüz ortalama ve gece ortalama kan basıncı değerlerinin karşılaştırılması

\begin{tabular}{|c|c|c|c|}
\hline & $\begin{array}{l}\text { Mikroalbuminüri } \\
\text { olanlar }\end{array}$ & $\begin{array}{l}\text { Mikroalbuminüri } \\
\text { olmayanlar }\end{array}$ & $\begin{array}{l}\text { P de- } \\
\text { ğeri* }\end{array}$ \\
\hline $\begin{array}{l}\text { 24sa kan ba- } \\
\text { sıncı(mmHg) } \\
\text { Sistolik } \\
\text { Diastolik }\end{array}$ & $\begin{array}{l}109(105.6-112) \\
72.4(69.2-76)\end{array}$ & $\begin{array}{l}101.5(95-104.3) \\
62.5(59.8-63.8)\end{array}$ & $\begin{array}{l}<0.05 \\
<0.05\end{array}$ \\
\hline $\begin{array}{l}\text { Gündüz kan } \\
\text { basıncı(mmHg) } \\
\text { Sistolik } \\
\text { Diastolik }\end{array}$ & $\begin{array}{l}113(110.4-115.2) \\
74.7(69.7-78.3)\end{array}$ & $\begin{array}{l}105(102-108.4) \\
65(63.8-67.1)\end{array}$ & $\begin{array}{l}<0.05 \\
<0.05\end{array}$ \\
\hline $\begin{array}{l}\text { Gece kan } \\
\text { basıncı(mmHg) } \\
\text { Sistolik } \\
\text { Diastolik }\end{array}$ & $\begin{array}{l}102(101-104.5) \\
69(67-71.5)\end{array}$ & $\begin{array}{l}97(96-99.3) \\
65(63.3-68.9)\end{array}$ & $\begin{array}{l}>0.05 \\
>0.05\end{array}$ \\
\hline
\end{tabular}

Tablo 3. Mikroalbuminürisi olan ve olmayan hastaların klinik-demografik özellikleri

\begin{tabular}{l|l|l|l}
\hline & $\begin{array}{l}\text { Mikroalbuminüri } \\
\text { olanlar (n) }\end{array}$ & $\begin{array}{l}\text { Mikroalbuminüri } \\
\text { olmayanlar(n) }\end{array}$ & $\begin{array}{l}\text { P de- } \\
\text { ğeri * }\end{array}$ \\
\hline Sayı & 56 & 33 & \\
\hline Kız/erkek & $18 / 38$ & $18 / 15$ & $<0.05$ \\
\hline Retinopati & 4 & 3 & $>0.05$ \\
\hline Sol ventrikül hipertrofisi & 3 & - & $>0.05$ \\
\hline HbA1c yüksekliği & 54 & 9 & $<0.001$ \\
\hline Nöropati & 2 & - & $>0.05$ \\
\hline $\begin{array}{l}\text { Anne-babadan en az biri } \\
\text { üniversite mezunu }\end{array}$ & 3 & 11 & $<0.001$ \\
\hline Kardeş sayısı (>2 kardeş ) & 40 & 18 & $<0.05$ \\
\hline Erken doğum öyküsü & 5 & 3 & $>0.05$ \\
\hline Obezite & 7 & 4 & $>0.05$ \\
\hline \multicolumn{2}{c}{ *:Pearson ki-kare testi ile $p<0.05$ anlamlı kabul edilmiştir }
\end{tabular}

Ayrıca mikroalbuminürisi olan ve olmayan grup arasındaki 24 saatlik,gündüz ve gece kan basıncı değerlerinin karşılaştırıması tablo 2'te verilmiştir.Hipertansiyonu olan 19 hastanın tamamında kötü metabolik kontrol,diyet uyumsuzluğu ve yüksek $\mathrm{HbA1c}$ düzeyi vardı. Mikroalbuminürik 56 hastanın 40(\%71.4)'ında takip süresi $>5$ yıldı. Mikroalbuminüri olmayan 33 hastanın 22(\%66.6)'sinin 24 saatlik tansiyon holteri ise non-dipper idi (13 sistolik,3 diastolik). Nondipper olan 16 hastanın takip süresi $>5$ yıldı. Buna göre her iki grup arasında 24 saatlik tansiyon holteri ve gün ortalaması değerleri açısından anlamlı farklıık saptanmış olup non-dipping fenomeni açısından anlamlı derecede fark yoktur. Mikroalbuminürisi olan grubun $\mathrm{HbA1c}$ ortalaması 10.9 \pm 2.3 iken, mikroalbuminürisi olmayan grupta $6.7 \pm 2.7$ idi $(p<0.001)$. Iki grubun klinik-demografik özellikleri

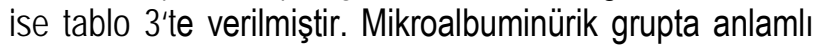

derecede erkek cinsiyet hakimiyeti mevcuttu $(p<0.01)(E / K: 2.1)$. Her iki grup arasında yaş ile 24 sa $K B$ arasında ise anlamlı derecede ilişki bulunmadı( $p>0.05)$. Benzer şekilde yaş ile gündüz ve gece KB ortalamaları ile dipper-nondipper olma durumuna göre de her iki grup arasında anlamlı ilişki saptanmadı ( $p>0.05$ ). Diyabetik retinopati ve kardiyak tutulum açısından bakıı dığında her iki grup arasında anlamlı bir fark görülmedi $(p>0.05)$. HbA1c düzeyleri mikroalbuminürik grupta anlamlı derecede yüksek bulundu(p<0.001). Mikroalbuminürik gruptaki 2 hastada EMG ile doğrulanmış periferik distal nöropati bulguları vardı. Sosyodemografik özellikler açısından bakıldığında ise ebeveynlerden en az birinin üniversite mezunu olduğu hasta sayısı mikroalbuminürik grupta $3(\% 5.3)$ iken, mikroalbuminürik olmayan grupta anlamlı derecede yüksek olarak 11(\%33.3) idi ( $p<0.01)$. Benzer şekilde kardeş sayısı ise mikroalbuminürik grupta $40(\% 71.4)$ hastada >2kardeş iken, mikroalbuminürik olmayan grupta $8(\% 24.2)$ idi $(p<0.05)$.Her iki grupta da erken doğum öyküsü ve obezite benzer orandaydı $(p>0.05)$.

\section{Tartışma}

Mikroalbuminüri tip1 DM hastalarında diyabetik nefropatinin en erken bulgusudur. Literatürde özellikle uzun süredir takipli diyabet hastalarında ve yüksek $\mathrm{HbA} 1 \mathrm{c}$ düzeyi ile güçlü derecede prognostik ilişki olduğu pek çok çalışmada kanıtlanmıştır(3,4). Çalışmamızda da literatürle uyumlu şekilde mikroalbuminürik hastaların $\mathrm{HbA} 1 \mathrm{c}$ düzeyleri ve takip süreleri mikroalbuminürisi olmayan hastalara göre anlamlı derecede yüksekti $(p<0.05)$.

Mikrovasküler komplikasyonlar açısından önemli olan bir diğer klinik gösterge ise tansiyon değerlerindeki bozulmadır. Yapılan birçok çalışmada tip 1 DM hastalarında özellikle nefropatinin erken aşamasında normalde olması gereken gece tansiyon düşüşünün(dipping fenomen) olmadığı görülmüştür(5,6).Mikroalbuminürisi olan grupta 24saatlik tansiyon holter sonuçlarından özellikle sistolik HT sıklığı mikroalbuminürisi olmayan gruba göre daha anlamlı derecede fazlaydı $(p<0.05)$. Gece düşüşü (non-dipping fenomen) açısından bakıldığında ise her iki grup arasında anlamlı fark yoktu $(p>0.05)$. Mikroalbuminürisi olmayan grupta 13 hasta sistolik nondipper iken, 3hasta diastolik non dipperdı.Mikroalbuminürik 56 hastanın sadece 9(\%16)'unda 24 saatlik tansiyon holterinde anormallik yoktu Bu sonuçlar bize diyabetik nefropatinin en erken bulgusunun sadece mikroalbuminüri olmadığını aynı zamanda tansiyon değerlerindeki küçük bozulmaların da erken bulgu olabileceğini,özellikle takip süresi >5yıl olan hastalarda mikroalbuminüri saptanmasa da 24 saatlik tansiyon holteri yapmanın gerekli olabileceğini düşündürmektedir.Tip 1 DM hastalarında kötü metabolik kontrol ve buna bağlı yüksek HbA1c düzeyleri literatür ile uyumlu olarak bi- 
zim çalışmamızda da esas belirleyici faktörlerden biri olarak bulundu(7). Sistolik HT ve mikroalbuminürisi olan hastaların tamamı ile mikroalbuminurisi olmayan ancak non dipper fenomeni olan 16 hastadan 12 sinin yüksek HbA1c düzeyleri mevcuttu $(p<0.05)$.

Yaş ve cinsiyet ile mikroalbuminüri ilişkisi açısından incelendiğinde literatürde çok değişik sonuçlar karşımıza çıkmaktadır. Bazı çalışmalarda cinsiyet ve mikroalbuminüri arasında bir ilişki saptanmamışken(8,9), bazı çalışmalarda kızlarda daha sık olduğunu göstermiştir(10). Çalışmamızda mikroalbuminürisi olan grupta anlamlı derecede erkek cinsiyet hakimiyeti vardır $(p<0.05)$. Yaş ilişkisi açısından bakıldığında ise her iki grup arasında yaş ile 24 sa $\mathrm{KB}$,gece-gündüz $\mathrm{KB}$ ortalamaları ve dipper-nondipper olma durumu arasında anlamlı derecede ilişki buluna$\operatorname{mad}(p>0.05)$. Çalışmamızda cinsiyetler arası kan basıncı değerlerinin ayrıntılı şekilde incelenmemiş olması çalışmamız için bir kısıtılık olmakla birlikte bu verinin araştırılması gelecek çalışmalar için etkin bir faktör olabilirdi. Mikrovasküler komplikasyonlardan diyabetik retinopati, nöropati ve sol ventrikül disfonksiyonu genellikle erişkinlik döneminde görülmekle birlikte uzun süredir takipli ve kötü metabolik kontrollü ergen tip 1 diyabet hastalarında da karşımıza çıkmaktadır. Mikrovasküler komplikasyonlar açısından bakıldığında özellikle diyabetik retinopatide hem tip1 DM hem de tip2 DM hastalarında hastalık süresi ve yüksek sistolik kan basıncı değerleri risk faktörü olarak bulunmuştur(11). Diğer bir erişkin çalışmasında da mikroalbuminüri ve sistolik kan basıncı yüksekliği olan hastalarda belirgin sol ventrikül disfonksiyonu olduğunu göstermiş̧ir(12). Çalışmamızda mikroalbuminürisi olan grupta 4 hastada retinopati, 3 hastada sol ventrükül hipertrofisi,2 hastada da periferik nöropati mevcuttu ve bu hastaların tamamında $\mathrm{HbA} 1 \mathrm{c}$ seviyesi anlamlı derecede yüksekti. Mikroalbuminürisi olmayan grupta ise 3hastada retinopati varken, nöropati ve kalp tutulumu yoktu( $p>0.05)$. Mikroalbuminürisi olan 56 hastanın 54 'ünde $\mathrm{HbA} 1 \mathrm{c}$ düzeyi yüksek saptanmış ve bunlardan 36 hastaya ACE inhibitörü,18hastaya da Anjiotensin 2 reseptör blokeri ile tedavi başlanmıştı. Tedavi seçiminde literatürde her iki grup ilaç da önerilmekle birlikte hangi hastada hangi ilacın öncelikli tercih edilmesi gerektiği netlik kazanmamıştır(13,14). Hastalarımızda da literatür ile uyumlu şekilde her iki ilacı alan hastalar arasında klinik cevap açısından anlamlı derecede fark saptanmadı. Bu hastalarda klinik cevabı etkileyen en önemli faktör kötü metabolik kontrol ve yüksek HbA1c düzeyi ve diyete uyumsuzluktur. Tedavi alan hastaların büyük bir kısmının diyete uyum sürecini aksatıkları dönemlerde tekrarlayan medikal tedavi intiyaçları olduğu görülmüştür(15,16).

Yapılan çalışmalarda obezite ile mikroalbuminüri arasında ilişki bulunurken mikroalbuminürisi olan 56 hastamızın sadece 7 si obezdi(p>0.05)(10,17). Hasta popülasyonumuzun genellikle sosyoekonomik ve sosyokültürel olarak dar gelirli ailelerden oluştuğunu varsayarsak bu oranın düşüklüğünü beslenme yetersizliği ile açıklayabiliriz. Sosyoekonomik ve sosyokültürel durumun hastalık üzerine etkisi de araştırımış olan bir diğer konudur. Secrets ve arkadaşlarının yaptıkları 317 hastalık bir erişkin çalışmasında tip 1 diyabete bağı komplikasyonlardan ölen hastaların çoğunun düşük sosyoekonomik-sosyokültürel duruma sahip bireylerden olduğu gösterilmiştir(18). Diğer bir çalışma ise komplikasyon sıklığının sosyokültürel düzeyle ilişkisi olmasa da diyete uyum ve davranışsal tedavi sürecinin bu hastalarda iyi olmadığını göstermiştir(19). Mikroalbuminürik hastalarımızın sadece 3 tanesinde anne-babadan en az biri üniversite mezunuyken, mikroalbuminürik olmayan grupta bu sayı 11 idi $(p<0.05)$. Benzer şekilde mikroalbuminürik olmayan grupta anne-babadan en az birinin üniversite mezunu olduğu 11 hastamızın tamamının $\mathrm{HbA} 1 \mathrm{c}$ düzeyleri normaldi. Mikroalbuminürik 56 hastamızın 40 tanesinde ikiden fazla kardeş öyküsü mevcuttu. Bu hastaların 29'unun ailesi diyete uyumun kötü olduğunu ifade ederken,diyete uyduklarını ifade eden 11 hastanın tamamının $\mathrm{HbA} 1 \mathrm{c}$ düzeyleri de yüksekti. Diyabet eğitiminin ne kadar iyi yapıldığı kadar ne kadar anlaşılır ve uygulanır olduğunun da hastalığın seyri ve komplikasyonların gelişimi açısından önemi böylece anlaşılmış oluyor(20,21).

Çalışmamız retrospektif olduğu için kayıtlarda eksiklikler olsa da klinik demografik özellikler açısından kayıtlarına ulaşılabilen 89 hasta diyabetik nefropati ile tip 1 DM arasındaki prognostik özellikleri ortaya koyması açısından anlamlıdır.Diyabetik nefropati için tanımlanmış birçok prognostik faktör olmakla birlikte çalışmaların farklı sonuçlar elde etmesi konu ile ilgili görüşbirliği için çok sayıda çaIışma yapılmasına intiyaç olduğunu göstermektedir.

Sonuç olarak Tip 1 DM tanılı hastalarda diabetik nefropatinin takibi olarak mikroalbuminürinin yanında 24saatlik tansiyon holteri yapılması erken tanı için gerekli ve önemli olabilir. Özellikle takip süresi $>5 y$ Il olan ya da yüksek $\mathrm{HbA} 1 \mathrm{c}$ seviyesi olan hastalar ile sosyokültürel-sosyoekonomik olarak geri durumdaki ailelerin diyabet eğitimleri ve tedavi takipleri daha dikkatli ve gerekirse daha sık aralıklarla yapılması gerekebilmektedir.

\section{Açıklamalar}

Çalışma için gerekli izin Hatay Devlet Hastanesinden 29634685-929 sayı numarası ile 16/04/2020 tarihinde alınmıştır

\section{Kaynaklar}

1. Basiratnia M, Abadi SF, Amirhakimi GH, Karamizadeh Z, Karamifar $\mathrm{H}$. Ambulatory blood pressure monitoring in children and adolescents with type-1 diabetes mellitus and its relation to diabetic control and microalbuminuria.Saudi J Kidney Dis Transpl. 2012;23(2):311-315.

2. Zabeen B, Nahar J, Islam N, Azad K, Donaghue K. Risk Factors Associated with Microalbuminuria in Children and Adolescents with Diabetes in Bangladesh. Indian J Endocrinol Metab. 2018;22(1):85-88.

3. Mateo-Gavira I, Vílchez-López FJ, García-Palacios MV, Carral-San 
Laureano F, Jiménez-Carmona S, Aguilar-Diosdado M. Nocturnal blood pressure is associated with the progression of microvascular complications and hypertension in patients with type 1 diabetes mellitus.J Diabetes Complications. 2016;30(7):1326-1332

4. Lévy-Marchal C, Sahler C, Cahané M, Czernichow P; GECER Study Group. Risk factors for microalbuminuria in children and adolescents with type 1 diabetes. J Pediatr Endocrinol Metab. 2000;13(6):613-620. 5. Darcan S, Goksen D, Mir S, Serdaroglu E, Buyukinan M, Coker M et al. Alterations of blood pressure in type 1 diabetic children and adolescents.Pediatr Nephrol. 2006;21(5):672-676.

6.Perrin NE, Torbjörnsdotter T, Jaremko GA, Berg UB. Risk markers of future microalbuminuria and hypertension based on clinical and morphological parameters in young type 1 diabetes patients. Pediatr Diabetes. 2010;11(5):305-313.

7. Machnica L, Deja G, Jarosz-Chobot P. Hypertension and prehypertension in children and adolescents with diabetes type 1.Pediatr Endocrinol Diabetes Metab. 2008;14(4):215-219.

8. Lopes CA, Lerário AC, Mion D Jr, Koch V, Wajchenberg BL, Rosenbloom AL. Ambulatory blood pressure monitoring (ABPM) in normotensive adolescents with type 1 diabetes. Pediatr Diabetes. 2002;3(1):3136.

9. Shikata K, Kodera R, Utsunomiya K, Koya D, Nishimura R, Miyamoto $S$ et al.; JDCP study group. Prevalence of albuminuria and renal dysfunction, and related clinical factors in Japanese patients with diabetes: The Japan Diabetes Complication and its Prevention prospective study 5. J Diabetes Investig. 2020;11(2):325-332.

10. Staiano AE, Morrell M, Hsia DS, Hu G, Katzmarzyk PT. The Burden of Obesity, Elevated Blood Pressure, and Diabetes in Uninsured and Underinsured Adolescents. Metab Syndr Relat Disord. 2016;14(9):437441.

11. Wan Nazaimoon WM, Letchuman R, Noraini N, Ropilah AR, Zainal $\mathrm{M}$, Ismail IS et al.Systolic hypertension and duration of diabetes mellitus are important determinants of retinopathy and microalbuminuria in young diabetics. Diabetes Res Clin Pract. 1999;46(3):213-221.

12. Aggarwal HK, Jain D, Mor S, Yadav RK, Jain P. Prevalence and Clinical Correlates of Microalbuminuria in Patients with EssentialHypertension - A Tertiary Care Center Cross Sectional Study. J Assoc Physicians India. 2018;66(5):30-34.

13. Chiarelli F, Trotta D, Verrotti A, Mohn A. Treatment of hypertension and microalbuminuria in children and adolescents with type 1 diabetes mellitus. Pediatr Diabetes. 2002;3(2):113-124.

14. Hornung RJ, Reed PW, Mouat F, Jefferies C, Gunn AJ, Hofman PL. Angiotensin-converting enzyme-inhibitor therapy in adolescents with type 1 diabetes in a regional cohort: Auckland, New Zealand from 2006 to 2016. J Paediatr Child Health. 2018;54(5):493-498.

15. Zheng XY, Luo SH, Wei XY, Ling P, Ai HY, Liu ZY et al. Related factors for microalbuminuria in adult type 1 diabetes patients of short disease duration. Zhonghua Yi Xue Za Zhi. 2020;100(6):419-423.

16. Lind M, Pivodic A, Svensson AM, Ólafsdóttir AF, Wedel H, Ludvigsson $\mathrm{J}$. HbA1c level as a risk factor for retinopathy and nephropathy in children and adults with type 1 diabetes: Swedish population based cohort study.BMJ. 2019; 28;366:14894.

17. Fellinger $P$, Fuchs $D$, Wolf $P$, Heinze $G$, Luger $A$, Krebs M, Winhofer $Y$. Overweight and obesity in type 1 diabetes equal those of the general population. Wien Klin Wochenschr. 2019;131(3-4):55-60.

18. Secrest AM, Costacou T, Gutelius B, Miller RG, Songer TJ, Orchard TJ. Association of socioeconomic status with mortality in type 1 diabetes: the Pittsburgh epidemiology of diabetes complications study.Ann Epidemiol. 2011;21(5):367-373.

19. Mühlhauser I, Overmann $H$, Bender R, Bott $U$, Jörgens $V$, Trautner C, Siegrist J, Berger M. Social status and the quality of care for adult people with type I (insulin-dependent) diabetes mellitus--a populationbased study. Diabetologia. 1998;41(10):1139-1150.

20. Sochett EB, Poon I, Balfe W, Daneman D. Ambulatory blood pressure monitoring in insulin-dependent diabetes mellitus adolescents with and without microalbuminuria. $\mathrm{J}$ Diabetes Complications.
1998;12(1):18-23.

21. Markuszewski L, Ruxer M, Szadkowska A, Bodalska J, Bissinger A. Evaluation of blood pressure changes by 24hours ambulatory blood pressure monitoring (ABPM) in young, normotensive patients with diabetes mellitus type I. Pol Merkur Lekarski. . 2006;20(115):32-3 5 . 